\title{
Levantamento de Orchidaceae em quatro fragmentos de Campos de Altitude em Campos do Jordão, SP, Brasil ${ }^{1}$
}

\author{
Gabriel Franco Gonçalves ${ }^{2,5}$, Daniela Sampaio ${ }^{3}$ e Fábio de Barros ${ }^{4}$
}

Recebido: 2.04.2015; aceito: 16.09.2015

\begin{abstract}
Taxonomic survey of the Orchidaceae in four highland fields fragments in Campos do Jordão, São Paulo State, Brazil). Orchidaceae is one of the largest families of Angiosperms, also being one of the richest and with high degree of endemism in the Atlantic Forest, a biome that includes Mixed Rain Forest and Highland Fields, typical of Campos do Jordão. This study aimed to survey the Orchidaceae species present in four highland fields in an Area of Environmental Protection belonging to the Instituto Presbiteriano Mackenzie in Campos do Jordão, São Paulo State, in the district of Umuarama. Monthly expeditions were made from February 16, 2013 to February 15, 2014. In this period, 12 species belonging to nine genera of Orchidaceae were collected. The most representative genera were Coppensia (three species) and Habenaria (two species), being the remaining genera represented by only one species. Several factors that endanger the integrity of these environments were observed, despite these environments being so little valued and not studied enough.
\end{abstract}

Keywords: Area of Enviromental Protection, Atlantic Forest, Taxonomy

RESUMO - (Levantamento de Orchidaceae em quatro fragmentos de Campos de Altitude em Campos do Jordão, SP, Brasil). Orchidaceae é uma das maiores famílias das Angiospermas, sendo também uma das mais ricas e com mais alto grau de endemismo na Mata Atlântica, bioma que inclui a Floresta Ombrófila Mista e os Campos de Altitude, típicos da região de Campos do Jordão. Este trabalho teve como objetivo fazer um levantamento das espécies de Orchidaceae ocorrentes em quatro campos de altitude em uma Área de Proteção Ambiental pertencente ao Instituto Presbiteriano Mackenzie em Campos do Jordão, Estado de São Paulo, no bairro de Umuarama. Foram realizadas expedições mensais de 16 de fevereiro de 2013 até 15 de fevereiro de 2014. Foram coletadas, ao todo, 12 espécies pertencentes a nove gêneros, sendo que desses, os mais representativos foram Coppensia (três espécies) e Habenaria (duas espécies), os demais representados por apenas uma espécie. Foram observados muitos fatores que colocam em risco a integridade desses ambientes já tão pouco valorizados e estudados.

Palavras-chave: Área de Proteção Ambiental, Mata Atlântica, Taxonomia

\section{Introdução}

Orchidaceae é uma das maiores famílias das Angiospermas, compreendendo de 1/10 a 1/14 das espécies do grupo (Dressler 1981), e possuindo 26.454 espécies distribuídas em 735 gêneros (Chase et al. 2015). No Brasil, a família é representada por cerca de 240 gêneros e 2.440 espécies (Barros et al. 2013), sendo que mais de 700 espécies são encontradas no Estado de São Paulo, distribuídas em 147 gêneros (Barros et al. 2013). A família apresenta distribuição cosmopolita (com exceção das regiões de clima polar ou desérticas), com maior representatividade nos trópicos e subtrópicos, principalmente em florestas tropicais da Ásia e das Américas (Dressler 1993, 2005). A família é composta por ervas perenes, $75 \%$ das quais são epífitas (Atwood 1986, Pinheiro et al. 2004), mas também podem ser terrícolas, rupícolas ou mico-heterotróficas aclorofiladas. Em suas flores estão os principais caracteres diagnósticos, e estas podem apresentar grande variação com relação ao tamanho, forma e cor, porém suas estruturas são arranjadas de maneira bastante uniforme na maioria das espécies (Pabst \& Dungs 1975, 1977, Pinheiro et al. 2004, Rosa \& Affonso 2009, Guimarães 2010).

1. Trabalho de Conclusão de Curso do primeiro Autor

2. Universidade Presbiteriana Mackenzie, Centro de Ciências Biológicas e da Saúde, 181, 01241-001, São Paulo, SP, Brasil

3. Universidade Estadual Paulista, Departamento de Biociências, Letras e Ciências Exatas, 2265, 15054-000, São José do Rio Preto, SP, Brasil

4. Instituto de Botânica, Núcleo de Pesquisa Orquidário do Estado, Av. Miguel Estéfano 3687, 04301-902, São Paulo, SP, Brasil

5. Autor para correspondência: gabriel_kominami@hotmail.com 
Orchidaceae é reconhecida por Stehmann et al. (2009) como a família com a maior riqueza dentro do domínio fitogeográfico da Mata Atlântica, com 1.257 espécies ( $8 \%$ do total registrado para este bioma) distribuídas em 176 gêneros. A família também possui um elevado grau de endemismo, sendo que $10 \%$ dos gêneros e $63 \%$ das espécies são elementos exclusivos do Domínio Atlântico. Incluídas dentro deste bioma, estão a Floresta Ombrófila Mista e os campos de altitude, tipos de vegetação típicos da região de Campos do Jordão.

Os campos de altitude são áreas cuja altitude varia de 1.200 a 2.900 metros (Martinelli 2007), ocorrendo nos três principais sistemas orográficos do país: Cadeia do Espinhaço, Serra da Mantiqueira e Serra do Mar (Vasconcelos 2011). Os campos de altitude localizados no Bioma Mata Atlântica estão presentes nos Estados do Paraná, Santa Catarina, São Paulo e Rio de Janeiro, ocorrendo junto de formações florestais circundantes devido a razões relacionadas ao clima e às condições pedológicas (Mocochinski \& Scheer 2008).

Estudos florísticos realizados em campos de altitude (Caiafa \& Silva 2005, Mocochinski \& Scheer 2008, Barberena 2010, Rezende et al. 2013), revelaram grande diversidade de gêneros e espécies de Orchidaceae, principalmente espécies terrícolas, algumas poucas epífitas sobre árvores espalhadas pelo campo ou também, muito frequentemente, rupícolas. Por apresentarem diversos mecanismos de adaptação morfológica, anatômica e fisiológica (Silva et al. 2006) que garantem sua adaptação aos mais diversos ambientes, muitas espécies de orquídeas acabam ocorrendo em grande quantidade nesse tipo de vegetação.

O município de Campos do Jordão (SP), apresenta uma vegetação predominante de Floresta Ombrófila Mista e campos de altitude, com 88 espécies de orquídeas com ocorrência nessa região, segundo os dados de acervos de herbários disponíveis no site do SpeciesLink, pertencente ao Centro de Referência em Informação Ambiental (CRIA) (www.splink.org. br). Essa região, que apesar de apresentar um grande número de espécies, principalmente de Orchidaceae, não possuía nenhum trabalho específico de flora nem no município de Campos do Jordão nem nos municípios próximos; apenas alguns poucos trabalhos, como o de Pereira-Silva et al. (2007) que fizeram uma caracterização florística da vegetação lenhosa de um fragmento urbano de floresta ombrófila mista e o de Arzolla et al. (2007) que registraram nova ocorrência de uma espécie de Gesneriaceae de coletas isoladas (Arzolla et al. 2007). Para os campos de altitude, não havia, até o momento, nenhum trabalho que procurasse inventariar as orquídeas ocorrentes, não obstante esse tipo de vegetação se encontre tão ameaçado pelo avanço do crescimento urbano, o que ressalta a importância deste estudo para se obter um conhecimento mais detalhado sobre as espécies da região, enriquecer o conhecimento sobre a flora local e auxiliar na preservação desses habitats. Por conseguinte, este estudo teve como objetivos realizar um levantamento florístico das espécies de Orchidaceae em quatro fragmentos de campos de altitude dentro de uma Área de Proteção Ambiental pertencente ao Instituto Presbiteriano Mackenzie na região de Campos do Jordão, Estado de São Paulo.

\section{Material e métodos}

Área de Estudo - A área de pesquisa, pertencente ao Instituto Presbiteriano Mackenzie, localiza-se no bairro de Umuarama, município de Campos do Jordão, Estado de São Paulo, no médio Vale do Paraíba na Serra da Mantiqueira, com as coordenadas centrais $22^{\circ} 45^{\prime} \mathrm{S}$ e $45^{\circ} 35^{\prime} \mathrm{W}$, e uma altitude média de 1.800 metros, constituindo Área de Proteção Ambiental (Robim \& Pfeifer 1989). Sua extensão territorial é de 34.477,20 m². A área tem histórico de ações antrópicas como o plantio de Pinus spp. e ocorrência de queimadas antigas em áreas de Florestas. Tem sido utilizada como colônia de férias da Instituição com uso restrito a funcionários e pessoas autorizadas, e também para a realização de saídas a campo de determinadas disciplinas do curso de Ciências Biológicas da Universidade. A propriedade possui uma pousada, um laboratório de pesquisa e algumas poucas casas em pontos específicos, além de trilhas dentro da vegetação.

O local de estudo é caracterizado, junto ao sistema de classificação da vegetação brasileira do IBGE (1992), como fragmento residual de Floresta Ombrófila Mista, correspondente a Floresta Montana e Alto Montana, segundo Veloso et al. (1991), mas também, apresenta campos de altitude, locais no qual foi realizado o presente estudo. Os campos de altitude podem ser encontrados em substratos ígneos e metamórficos, em porções mais elevadas da Serra do Mar e da Serra da Mantiqueira do Sudeste brasileiro, com altitude acima de 1.500 metros, particularidades identificadas na plataforma de Campos do Jordão (Robim \& Pfeifer 1989, Safford 1999, Benites et al. 2003, Caiafa \& Silva 2005, Ribeiro et al. 2007). 
A amostragem da família Orchidaceae foi realizada em quatro fragmentos de campos de altitude naturais, com as mesmas características apresentadas por Mocochinski \& Scheer (2008), ou seja, uma formação vegetacional de fisionomia campestre e arbustiva, que inclui representantes de algumas famílias muito diversificadas, como Asteraceae, Melastomataceae, Bromeliaceae e Orchidaceae. Os campos de altitude da região são constituídos de vegetação natural não sendo fruto de desmatamento ou qualquer outro fator antrópico, porém junto a esses dois tipos de vegetação também é possível encontrar, com certa frequência, plantações de Pinus spp.

Elaboração da Flora - Foram realizadas expedições mensais do dia 16 de fevereiro de 2013 até 15 de fevereiro de 2014 com o intuito de localizar todas as espécies em estado reprodutivo. Todo material coletado foi devidamente montado em exsicata e incluído no Herbário da Universidade Presbiteriana Mackenzie (MACK).

Além disso, foram montadas fichas florais de cada material, por meio da fervura de uma flor em água e montagem das peças florais em ficha de cartolina apropriada (ficha de análise floral). Ilustrações das flores desmontadas de todas as espécies foram feitas a partir do material coletado e quatro delas quanto ao seu aspecto vegetativo. Também foram analisados materiais adicionais dos herbários SP, SPSF e UEC.

O material foi identificado com uso de chaves de identificação e literatura especializada (e.g. Lindley 1830, 1840, Rodrigues 1877, 1882, Cogniaux 1893, 1896,
1898, 1902, 1904, 1906, Hoehne 1949, Pabst \& Dungs 1975,1977 , Sprunger 1986). Por fim, foram elaboradas as descrições das espécies encontradas seguindo, na definição das estruturas morfológicas, a conceituação de Radford et al. (1974). Posteriormente, foram elaboradas chaves de identificação para as espécies. Neste trabalho a nomenclatura das espécies seguiu a Lista de Espécies da Flora do Brasil (Barros et al. 2015).

\section{Resultados e Discussão}

Ao todo foi coletado, durante o período de 12 meses, um total de 12 espécies em nove gêneros, sendo os mais representativos Coppensia com três espécies, sendo duas terrícolas e uma epífita e Habenaria com duas espécies terrícolas; os demais gêneros foram representados por apenas uma espécie. Predominaram as plantas terrícolas devido à restrição do inventário a áreas de vegetação campestre, porém algumas poucas epífitas foram encontradas em árvores isoladas no campo e foram consideradas neste inventário. Nenhuma espécie rupícola foi registrada para a região devido à ausência de formações rochosas na área de estudo. A análise de materiais de herbários permitiu que fossem encontradas mais 13 espécies de Orchidaceae coletadas em campos de altitude de outras localidades dentro do município de Campos do Jordão, e que não estão registrados em publicações, são essas: Brachystele subfiliformes, Cranichis candida, Gomesa gomezoides, G. ramosa, Habenaria achalensis, $H$. balansae, H. edwallii, H. melanopoda, H. secunda, $H$. subviridis, Liparis vexillifera e Coppensia montana.

Chave para identificação das espécies de Orchidaceae dos Campos de Altitude em Campos do Jordão

1. Plantas epífitas

2. Cauloma intumescido em pseudobulbo

3. Folhas lanceoladas, coriáceo-carnosas; inflorescência uniflora; flores vermelho-alaranjadas ... Hadrolaelia mantiqueirae

3. Folhas estreitamente oblongas, subcoriáceas; inflorescência em panícula; flores

predominantemente amarelas Coppensia hookeri

2. Cauloma não intumescido em pseudobulbo

4. Folhas estreitamente elípticas, coriáceas; inflorescência em racemo Anathallis rubens

4. Folhas tríquetas, carnosas; inflorescência em fascículo Octomeria gracilis

1. Plantas terrícolas

5. Cauloma intumescido em pseudobulbo

6. Inflorescência em racemo, raramente ramificada, nutante; labelo sem istmo Coppensia fuscans

6. Inflorescência em panícula, ereta; labelo com istmo Coppensia blanchetii

5. Cauloma não intumescido em pseudobulbo

7. Inflorescência em espiga

8. Folhas pecioladas, elípticas; flores verdes; labelo cuculado; pétalas lineares Prescottia stachyodes

8. Folhas sésseis, lanceoladas; segmentos florais brancos na face adaxial e castanho-claros

na face abaxial; labelo auriculado; pétalas lanceoladas

7. Inflorescência em racemo 
9. Inflorescência pilosa

10. Flores inteiramente avermelhadas a rosadas Sacoila lanceolata

10. Flores brancas com listras verdes Pelexia laminata

9. Inflorescência glabra

11. Segmento anterior das pétalas menor que o posterior; segmentos laterais do labelo menores que o mediano Habenaria parviflora

11. Segmento anterior das pétalas maior que o posterior; segmentos laterais do labelo maiores ou iguais ao mediano Habenaria repens

Anathallis rubens (Lindl.) Pridgeon \& M.W.Chase, Lindleyana 16(4): 250. 2001.

Figura 1 a

Epífita, simpodial; rizoma inconspícuo; caule não intumescido em pseudobulbo, 5-16 cm compr., envolto por bainhas simples. Folhas estreitamente elípticas a oblongas, coriáceas, 5-12 × 1,6-3 cm, ápice acuminado a arredondado, base atenuada. Inflorescência em racemo, apical, glabra, 5-37 cm compr.; flores amarelas, aromáticas; sépala dorsal lanceolada, 0,7-1,1 × 0,2-0,4 cm, ápice agudo, base séssil; sépalas laterais lanceoladas, 0,9-1,1 × 0,3-0,6 cm, ápice agudo, base séssil, formando um mento com o pé do ginostêmio; pétalas obovadas, $0,4-0,6 \times 0,2-0,3 \mathrm{~cm}$, ápice arredondado, base atenuada; labelo trilobado, pandurado, 0,5-0,6 × 0,2-0,3 cm, ápice retuso, base unguiculada, ca. 0,2 cm compr.; ginostêmio cilíndrico, 0,4-0,5 cm compr.; polínias duas; rostelo proeminente, laminar, 0,2-0,3 cm compr.; ovário articulado com o pedicelo, 0,2-0,3 cm compr.

Espécie epífita, coletada sobre árvores, uma próxima ao limite entre campo e mata fechada e outra numa área de campo com algumas árvores isoladas. Possui ampla distribuição no Brasil, ocorrendo nos Estados da Bahia, Paraíba, Pernambuco, Minas Gerais, Rio de Janeiro, São Paulo, Paraná, Rio Grande do Sul e Santa Catarina (Barros et al. 2015).

Material examinado: BRASIL. SÃo PAULo: Campos do Jordão, 16-II-2013, G.F. Gonçalves 24 (MACK); idem, 16-II-2013, G.F. Gonçalves 6 (MACK).

Material adicional examinado: BRASIL. BAHIA: Rio de Contas, 24-XI-1988, R.M. Harley 26267 (SP); Jussari, 2-IV-2002, T.B. Brier $1176 I$ (UEC); EsPíRITO SANTo: Santo Amaro, 15-I-1943, P.L. Krieger 320 (SP); Minas Gerais: Caeté, 13-I-1989, C.C. Reis 55 (UEC); Caldas, 12-II-1978, H.F. Leitão Filho et al. 1485 (UEC); idem, 29-II-1920, F.C. Hoehne s.n. (SP4739); idem, s.d., A. Regnell 424 (SP); Carrancas, XII-1999, A.O. Simões et al. 1022 (UEC); Poços de Caldas, 3-XII-1981, F. Barros 669 (SP); idem,
2-XII-1982, H.F. Leitão Filho 1855 (UEC); idem, 1-XII-1981, H.F. Leitão Filho et al. 4585 (UEC); Lima Duarte, 2-IV-2002, T.B. Brier 1176 (UEC); Santa Bárbara, 14-XII-1978, H.F. Leitão Filho et al. 9782 (SP); PARANÁ: Morretes, 25-I-1947, G. Hatschbach 844 (SP); idem, 7-I-1951, G. Hatschbach 2115 (SP); Rio de Janeiro: Petrópolis, s.d., C. Spannagel 92 (SP); São PaUlo: Campos do Jordão, 25-III-2013, T.E. Barreto 101 (SPSF); Cotia, 26-XIII-2006, F. Barros s.n. (SP 401808); Jundiaí, 14-I-41, O.C. Saés 2 (SP); Mariporã, 3-II-2005, M.C. Gobitta et al. 6 (SPSF); Miracatu: 25-I-1985, P. Martuscelli 96 (SP); Paranapiacaba, 7-I-1918, F.C. Hoehne s.n. (SP1209); idem, s.d., F.C. Hoehne s.n. (SP22502); São Paulo, 28-XIII-1921, F.C. Hoehne s.n. (SP3695); idem, 20-III-1991, R. Esteves s.n. (SP249612); idem, 8-I-1926, F.C. Hoehne s.n. (SP22503); idem, 8-I-1932, F.C. Hoehne s.n. (SP28756).

Coppensia blanchetii (Rchb.f.) Campacci, Bol. CAOB 62: 55. 2006.

Figuras $1 \mathrm{~b}, 2 \mathrm{a}$

Terrícola, simpodial, raízes fasciculadas, não intumescidas, cauloma intumescido em pseudobulbo, oval, 1,5-10 × 1,3-3 cm, 2(-3)-foliado no ápice, 2-foliado na base, envolto por bainhas adpressas, dísticas. Folhas lanceoladas, subcoriáceas, 10-64 × 1-3,3 cm, ápice acuminado, base séssil. Inflorescência em panícula, lateral, ereta, glabra, 68-220 cm compr. Flores predominantemente amarelas; sépala dorsal elíptica a ovada, 0,5-1 × 0,3-0,5 cm, ápice arredondado, base bruscamente atenuada, formando unguículo; sépalas laterais elípticas a lanceoladas, assimétricas, 0,6-1,3 × 0,2-0,4 cm, ápice arredondado, base bruscamente atenuada, formando unguículo; pétalas obovadas, 0,6-1,3 × 0,4-0,7 cm, ápice arredondado, base bruscamente atenuada, formando unguículo; labelo trilobado, 1,2-2,5 × 0,7-2,5 cm, dotado de calosidade complexa na região anterior, lobos laterais semi-elípticos, istmo $0,2-0,3 \mathrm{~cm}$ compr., lobo central romboide, ápice retuso; ginostêmio curto, cilíndrico, 


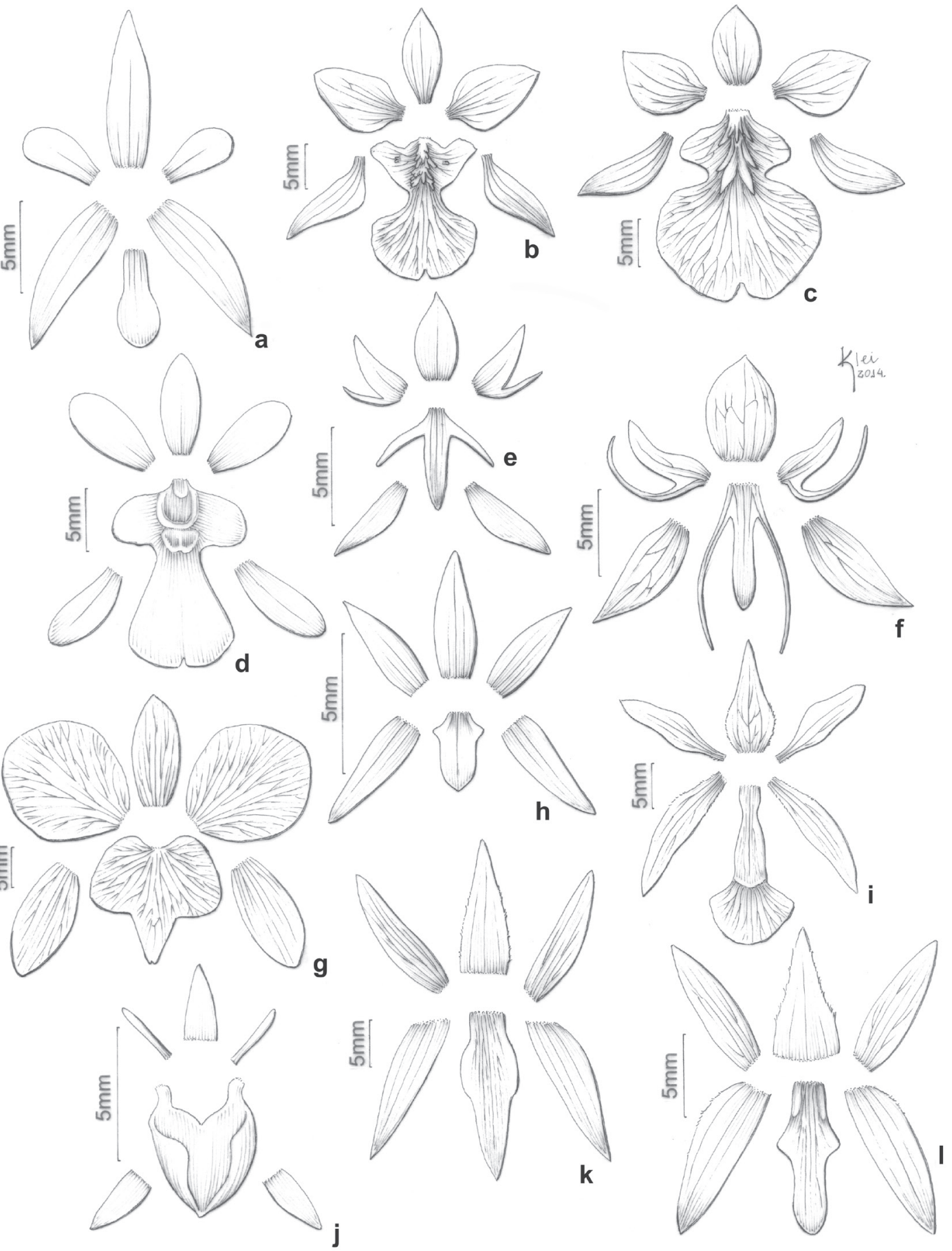

Figura 1. Peças do perianto distendidas de espécies de Orchidaceae ocorrentes em quatro fragmentos de Campos de Altitude em Campos do Jordão, SP, Brasil. a. Anathallis rubens (G.F. Gonçalves 24). b. Coppensia blanchetii (G.F. Gonçalves 29). c. Coppensia fuscans (G.F. Gonçalves 14). d. Coppensia hookeri (G.F. Gonçalves 31). e. Habenaria parviflora (G.F. Gonçalves 18). f. Habenaria repens (G.F. Gonçalves 17). g. Hadrolaelia mantiqueirae (G.F. Gonçalves 40). h. Octomeria gracilis. i. Pelexia laminata (G.F. Gonçalves 20). j. Prescottia stachyodes (G.F. Gonçalves 47). k. Sacoila lanceolata (G.F. Gonçalves 36). 1. Skeptrostachys balanophorostachya (G.F. Gonçalves 21).

Figure 1. Dissected perianth of species of Orchidaceae occurring in four fragments of Highland Fields in Campos do Jordão, São Paulo State, Brazil. a. Anathallis rubens (G.F. Gonçalves 24). b. Coppensia blanchetii (G.F. Gonçalves 29). c. Coppensia fuscans (G.F. Gonçalves 14). d. Coppensia hookeri (G.F. Gonçalves 31). e. Habenaria parviflora (G.F. Gonçalves 18). f. Habenaria repens (G.F. Gonçalves 17). g. Hadrolaelia mantiqueirae (G.F. Gonçalves 40). h. Octomeria gracilis (G.F. Gonçalves 3). i. Pelexia laminata (G.F. Gonçalves 20). j. Prescottia stachyodes (G.F. Gonçalves 47). k. Sacoila lanceolata (G.F. Gonçalves 36). 1. Skeptrostachys balanophorostachya (G.F. Gonçalves 21). 
0,2-0,5 cm compr., dotado de asas obovadas aos lados da cavidade estigmática, 01-0,2 cm compr.; antera elmiforme, ca. 0,3 cm compr.; polínias 2, dotadas de estipe e viscídio, polinário ca. $0,2 \mathrm{~cm}$ compr.; ovário e pedicelo $0,9-1,9 \mathrm{~cm}$ compr.

Os indivíduos coletados apresentam acentuado grau de variação fenotípica mesmo dentro de uma mesma população, porém os indivíduos de fragmentos de vegetação diferentes apresentaram variações mais marcantes. Materiais de herbário oriundos de outras localidades mostraram que essa variação é frequente e pode ser ainda maior do que a encontrada nos espécimes da região de estudo; além disso, $C$. blanchetii é muito semelhante a $C$. doniana, e, levando-se em consideração o alto grau de variação dentro do grupo, pode-se colocar em dúvida a relação entre as duas espécies e até mesmo sua validade como táxons distintos. Espécie amplamente distribuída no Brasil, ocorrendo desde o Nordeste nos Estados da Bahia e Pernambuco, no Sudeste, nos Estados de Minas Gerais, Rio de Janeiro e São Paulo, até o Sul, nos Estados do Paraná e Santa Catarina (Barros et al. 2015).

Material examinado: BRASIL. São PaUlo: Campos do Jordão, 16-II-2013, G.F. Gonçalves 11 (MACK); idem, 16-II-2013, G.F. Gonçalves 12 (MACK); idem, 16-II-2013, G.F. Gonçalves 13 (MACK); idem, 4-V-2013, G.F. Gonçalves 15 (MACK); idem, 26-IX-2013, G.F. Gonçalves 29 (MACK); idem, 17-VIII-2013, G.F. Gonçalves 35 (MACK); idem, 16-II-2013, G.F. Gonçalves 39 (MACK); idem, 21-III-2013, A. Albino et al. 6 (MACK).

Material adicional examinado: BRASIL. MINAS Gerais: Caldas, 21-I-1919, F.C. Hoehne s.n. (SP2880); Itamonte, 25-I-2009, F.F.V.A. Barbarena 136 (SP); Miguel Burnier, 27-I-1921, F.C. Hoehne s.n. (SP5121); Santa Bárbara, 11-II-1924, F.C. Hoehne s.n. (SP31681); idem, 21-I-1921, F.C. Hoehne s.n. (SP5064); São Paulo: Cunha, 14-III-1939, M. Kuhlmann \& A. Gehrt s.n. (SP40017); Campos do Jordão, 25-III-2013, T.E. Barreto 94 (SPSF); idem, 16-II-982, A. Amaral Jr. et al. 24 (SPSF); idem, I-1946, J.E. Leite 3870 (SP); Itararé, 2-X-1993, C.M. Sakuragi 359 (UEC); Salesópolis, 18-III-1958, M. Kuhlmann 4356 (SP); São Paulo, 2-II-1918, F.C. Hoehne s.n. (SP1473).

Coppensia fuscans (Rchb.f.) Campacci, Bol. CAOB 62: 55. 2006.

Figuras $1 \mathrm{c}, 2 \mathrm{~b}$

Terrícola, simpodial; raízes fasciculadas, filiformes; cauloma intumescido em pseudobulbo, oval a piriforme, 1,5-2,5 × 1-2,3 cm, 2-foliado no ápice, 1(-2)-foliado na base, envolto por bainhas adpressas, imbricadas, dísticas. Folhas lineares, subcoriáceas $12-38 \times 0,6-0,7 \mathrm{~cm}$, ápice agudo, base longamente atenuada. Inflorescência em racemo, raramente ramificada, lateral, nutante, glabra, 41-93 cm compr. Flores amarelas; sépala dorsal elíptica, 0,8-1 × 0,3-0,5 cm, ápice acuminado, base atenuada; sépalas laterais lanceoladas, assimétricas, 0,9-1,2 × 0,3-0,4 cm, ápice acuminado a arredondado, base atenuada; pétalas obovadas, 0,8-1,1 × 0,4-0,7 cm, ápice arredondado, base atenuada; labelo trilobado, dotado de calosidade central complexa, 1,1-2,1 × 1,2-1,8 cm, istmo ausente, lobos laterais semi-romboides, lobo central transversalmente elíptico, ápice retuso, base atenuada; ginostêmio cilíndrico, ca. $0,5 \mathrm{~cm}$ compr., dotado de asas obovadas aos lados da cavidade estigmática, ca. 0,2 cm compr.; ovário + pedicelo ca. 1,9 cm compr.

Espécie com baixa incidência, com apenas dois indivíduos vistos e coletados. Pode ser encontrada, no Brasil, nas regiões Sudeste, nos Estados de Minas Gerais, Espírito Santo, Rio de Janeiro e São Paulo, e na região Sul, nos Estados do Paraná e Santa Catarina (Barros et al. 2015).

Material examinado: BRASIL. São PAULO: Campos do Jordão, 16-II-2013, G.F. Gonçalves 2 (MACK); idem, 16-II-2013, G.F. Gonçalves 14 (MACK).

Material adicional examinado: BRASIL. Rio GRANDE Do Sul: Aparados da Serra, 15-I-1997, M. Frank s.n. (SP34009); SANTA Catarina: Lages, 11-III-1995, E.L. Borba et al. s.n. (SP355182); SÃo PaUlo: Campos do Jordão, 20-XII-1946, G.F.J. Pabst 338 (SP); idem, 24-XI-1992, S. Xavier \& E Caetano 314 (SP); idem, 22-IV-1996, N.K. Sakane s.n. (SP327183); idem, s.d., M. Kuhlmann s.n. (SP36639); São João da Boa Vista, 7-X-1995, R.R. Rodrigues et al. 390 (SP).

Coppensia hookeri (Rolfe) F.Barros \& L.R.S.Guim., Neodiversity 5 (1): 31. 2010.

Figura $1 \mathrm{~d}$

Epífita, simpodial, raízes fasciculadas, filiformes; cauloma intumescido em pseudobulbo piriforme, 3,5-5 × 0,5-1,2 cm, 2-foliado no ápice, 2-foliado na base, envolto por bainhas adpressas, imbricadas, dísticas. Folhas estreitamente oblongas, subcoriáceas, 7-23 $\times 1-1,5 \mathrm{~cm}$, ápice acuminado, base atenuada. Inflorescência em panícula, lateral, nutante, glabra, 29,5-50 cm compr. Flores predominantemente 


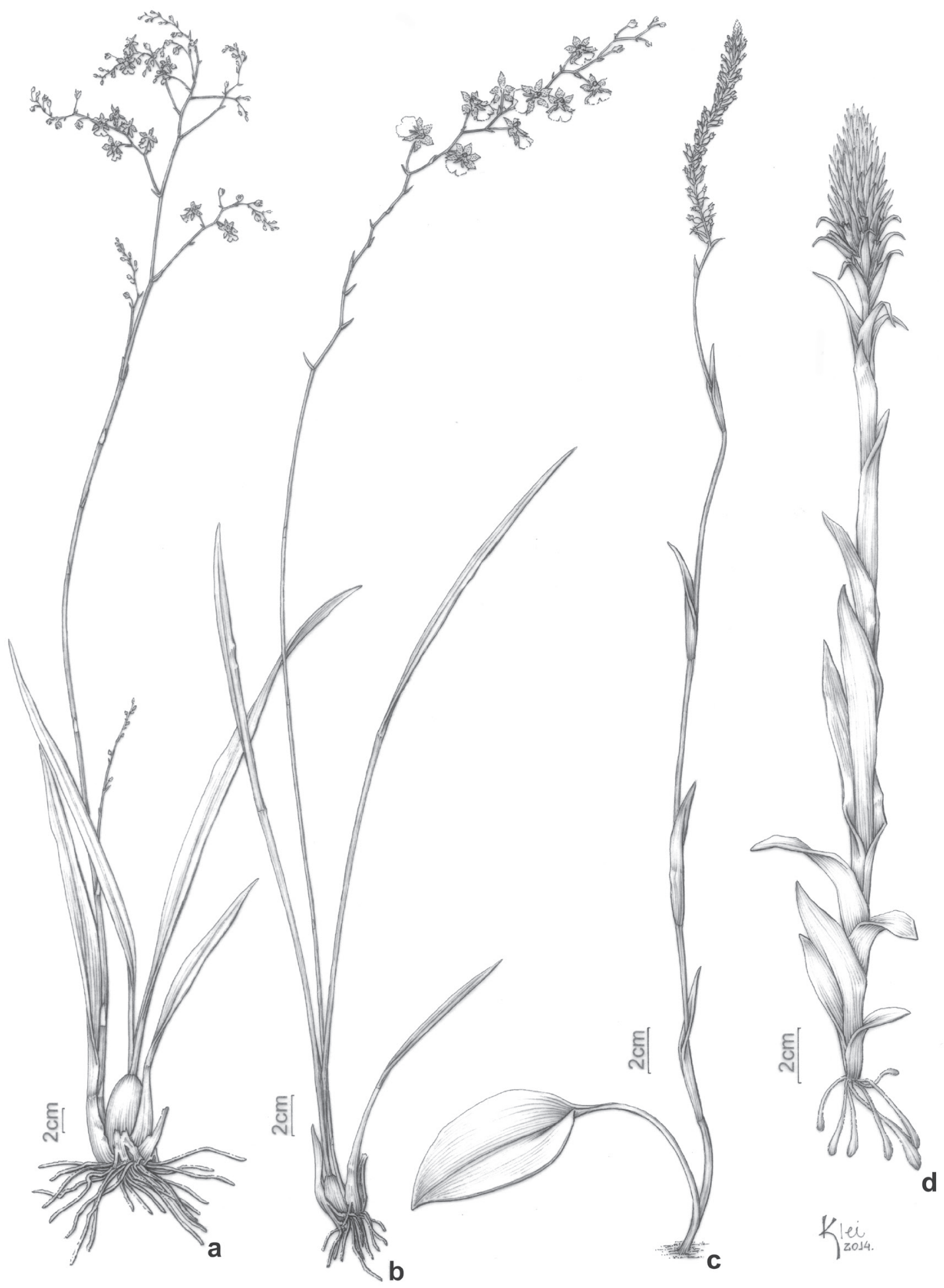

Figura 2. Aspecto geral de quatro espécies floridas de Orchidaceae ocorrentes nos fragmentos estudados de Campos de Altitude em Campos do Jordão, SP, Brasil. a. Coppensia blanchetii (G.F. Gonçalves 29). b. Coppensia fuscans (G.F. Gonçalves 14). c. Prescottia stachyodes (G.F. Gonçalves 47). d. Skeptrostachys balanophorostachya (G.F. Gonçalves 21).

Figure 2. General view of four flowered species of Orchidaceae occurring in the fragments of Higland Fields studied in Campos do Jordão, São Paulo State, Brazil. a. Coppensia blanchetii (G.F. Gonçalves 29). b. Coppensia fuscans (G.F. Gonçalves 14). c. Prescottia stachyodes (G.F. Gonçalves 47). d. Skeptrostachys balanophorostachya (G.F. Gonçalves 21). 
amarelas; sépala dorsal elíptica, $0,3-0,5 \times$ ca. $0,2 \mathrm{~cm}$, ápice acuminado, base atenuada; sépalas laterais lanceoladas, assimétricas, 0,3-0,4 × ca. 0,2 cm, ápice arredondado, base séssil; pétalas espatuladas, 0,4-0,5 × ca. $0,2 \mathrm{~cm}$, ápice cuspidado, base atenuada; labelo trilobado, dotado de calosidade complexa central, ca. $0,8 \times 0,6 \mathrm{~cm}$, lobos laterais semicirculares, istmo ca. $1 \mathrm{~cm}$ compr., lobo central obovado; ginostêmio cilíndrico, ca. 0,2 cm compr.; antera elmiforme; polínias 2, com estipe e viscídio; ovário + pedicelo ca. $0,6 \mathrm{~cm}$ compr.

Espécie frequente na mata e borda das trilhas, com uma coleta sobre árvore isolada e outra na borda do campo. Possui ampla distribuição geográfica em território nacional, ocorrendo nas regiões Nordeste, nos Estados da Bahia e Pernambuco, Sudeste, nos Estados de Minas Gerais, Rio de Janeiro e São Paulo e Sul, nos Estados do Paraná e Rio Grande do Sul (Barros et al. 2015).

Material examinado: BRASIL. SÃo PAULo: Campos do Jordão, 21-III-2013, G.F. Gonçalves 31 (MACK); idem, 15-II-2014, G.F. Gonçalves 42 (MACK).

Material adicional examinado: BRASIL. ParanÁ: Bacarena do Sul, 23-XI-1983, G. Hatschbach 46854 (SP); Cerro Azul, 27-III-79, G. Hatschbach 42188 (SP); Guaratuba, 14-IV-1983, R. Kummrow 2302 (SP); São José dos Pinhais, 6-IV-1983, G. Hatschbach 46261 (SP); Santa Catarina: Curitibanos, 3-I-1966, H.D. Bicalho 89 (SP); São PaUlo: Cananéia, 19-III-1984, F. Barros 990 (SP); Salesópolis, 11-III-2007, R.A. Costa et al. 33 (SP).

Habenaria parviflora Lindl., Gen. Sp. Orchid. Pl. p. 314. 1835.

Figura $1 \mathrm{e}$

Terrícola, simpodial; raízes fasciculadas apresentando tuberoides cilíndricos a fusiformes; caule 18-105 cm compr. Folhas dísticas, alternas, lanceoladas, membranáceas, 4-27 × 0,5-1,3 cm, ápice acuminado, base em bainha amplexicaule. Inflorescência em racemo, apical, glabra, 4,5-19 cm compr. Flores verdes; sépala dorsal elíptica, 0,3-0,5 × 0,2-0,3 cm, ápice acuminado, base atenuada; sépalas laterais lanceoladas, assimétricas, 0,4-0,6 × 0,1-0,2 cm, ápice agudo, base atenuada; pétalas bipartidas, segmento anterior linear, ca. $0,3 \mathrm{~cm}$ compr., segmento posterior lanceolado, assimétrico, falcado, 0,3-0,4 × 0,1-0,2 cm, ápice acuminado, base séssil; labelo tripartido, segmentos laterais lineares, 0,3-0,4 cm compr., segmento mediano oblanceolado, 0,3-0,7 × 0,1-0,2 cm; calcar fusiforme, 0,5-0,6 cm compr.; ginostêmio ca. 0,2 cm compr.; polínias não vistas, ovário ca. $1 \mathrm{~cm}$ compr.

Espécie abundante, principalmente em áreas com vegetação menos densa. Distingue-se facilmente de Habenaria repens, a outra espécie do gênero ocorrente na região, pelo tamanho menor de suas flores (figura 1e). Possui distribuição geográfica bastante ampla, ocorrendo no Norte, no Estado de Roraima, no Nordeste, nos Estados da Bahia e Sergipe, no CentroOeste, no Distrito Federal e no Estado de Goiás, no Sudeste, nos Estados do Espírito Santo, Minas Gerais, Rio de Janeiro e São Paulo e no Sul, nos Estados do Paraná Paraná, Rio Grande do Sul e Santa Catarina (Barros et al. 2015).

Material examinado: BRASIL. São PAUlo: Campos do Jordão, 17-II-2013, G.F. Gonçalves 5 (MACK); idem, 16-II-2013, G.F. Gonçalves 9 (MACK); idem, 21-III-2013, G.F. Gonçalves 18 (MACK); idem, 16-II-2013, G.F. Gonçalves 32 (MACK); idem, 15-II-2014, G.F. Gonçalves 41 (MACK).

Material adicional examinado: BRASIL. GoIÁs: São Gabriel de Goiás, 29-XII-2001, E.R. Pansarin \& L. Mickeliuns 345 (UEC); Minas GERAIS: Santo Antônio do Itambé, 4-IV-1982, L. Rossi et al. 3010 (SP); SANTA CATARINA: Lages, 11-XII-1995, E.L. Borba et al. 164 (UEC); São PaUlo: Atibaia, 27-III-1998, R.B. Singer 98/44 (UEC); Bananal, 28-III-2008, R.T. Polisel et al. 588 (SPSF); Biritiba Mirim, 28-XIII-1983, A Custodio Filho 2083 (SP); idem, 13-III-1984, A. Custodio Filho 2292 (SP); Bofete, 23-I-1996, V.C. Souza et al. 10354 (SP); Botucatu, 12-XII-2013, M.G. Marcusso 321 (SPSF); Campos do Jordão, 16-II-1982, A. Amaral Junior et al. 29 (SPSF); idem, 23-II-1945, J.E. Leite 3401 (SP); idem, 25-I-1935, M. Kuhlmann 4340 (SP); Caraguatatuba, 18-IV-2000, $W$. Foster et al. 414 (UEC); Cubatão, 15-III-1923, A. Gehrt 8226 (SP); Cunha, 29-III-1994, J.B. Baitello 453 (SPSF); idem, 30-III-1994, J.B. Baitello 580 (SPSF); Guarujá, 23-III-1938, F.C. Hoehne s.n. (SP1772); Iporanga, 23-IV-1994, V.C. Souza et al. 5969 (SP); Itapeva, III-2000, M.C.C. Ferreira et al 64 (UEC); Itararé, III-2000, M.C.C. Ferreira et al. 73 (UEC); Jundiaí, 4-III-2000, L.Y.S. Aona et al. 671 (UEC); idem, III-1995, R. Goldenberg 151 (UEC); Juquitiba, 8-III-1976, G. Davidse \& W.G. D'arcy 10931 (SP); idem, 26-III-1983, F. Barros 802 (SP); Mogi das Cruzes, 19-IV-1921, A. Gehrt 5500 (SP); Registro, 14-II-1965, G. Eiten \& W.D. Clayton 6072 (SP); Salesópolis, 1-III-1988, A Custodio Filho \& 
G.A.D.C. Franco 2895 (SPSF); idem, 16-III-1958, M. Kuhlmann 4340 (SP); São José do Barreiro, 20-I-2000, L. Freitas \& I.S.M. Gajardo 804 (UEC); São Miguel Arcanjo, 1-II-1978, G.T. Prance et al. 6908 (UEC); São Paulo, 13-IV-2001, L.D. Meireles et al. 158 (SPSF); idem, 15-III-1942, O. Handro s.n. (SP47515); idem, 9-XII-1930, A. Gehrt 28920 (SP); idem, 17-V-1942, L. Roth 872 (SP); idem, 1-XII-1933, M. Kuhlmann s.n. (SP31491); idem, 1-XII-1933, M. Kuhlmann s.n. (SP51493); idem, 6-IV-1918, F.C. Hoehne s.n. (SP1772); São Vicente, 17-III-2003, C. Moura et al. 26 (SPSF); Ubatuba, 10-II-1993, B. Martins et al. 29377 (SP); idem, 24-10-1995, M.D. Moraes s.n. (UEC034539); idem, 18-X-1998, R.B. Singer 98/101 (UEC); idem, 24-X-1995, M.D. Moraes s.n. (UEC034544); Vargem Grande do Sul, 14-XI-1997, J.H.A. Dutilh \& W. Marcondes-Ferreira 9 (UEC).

Habenaria repens Nutt., Gen. N. Amer. P1. 2: 190. 1818

Figura $1 \mathrm{f}$

Terrícola, simpodial; raízes fasciculadas apresentando tuberoides cilíndricos a fusiformes; caule 11-70 cm compr. Folhas lanceoladas a linearelípticas, alternas, imbricadas, membranáceas, 4-18 × 0,5-3 cm, ápice acuminado, base em bainha amplexicaule, atenuada. Inflorescência em racemo, apical, glabra, 4-32 cm compr. Flores verdes; sépala dorsal oval a elíptica, ca. $0,7 \times 0,4-0,6 \mathrm{~cm}$, ápice apiculado, base séssil; sépalas laterais lanceoladas, assimétricas, 0,6-0,9 × 0,2-0,4 cm, ápice apiculado, base séssil; pétalas bipartidas, segmento anterior linear, ca. $0,7 \times 0,1 \mathrm{~cm}$ compr., segmento posterior lanceolado, assimétrico, falcado, 0,5-0,7 × 0,1-0,2 cm, ápice agudo, base séssil; labelo tripartido, segmentos laterais lineares, $0,7-1 \times \mathrm{ca} .0,1 \mathrm{~cm}$, segmento mediano linear, ca. 0,7 × 0,1-0,2 cm, ápice arredondado, base séssil; calcar 1-1,2 cm compr.; ginostêmio ca. $0,2 \mathrm{~cm}$ compr., polínias não vistas; ovário + pedicelo ca. 1,2 cm compr.

Espécie encontrada com abundância, porém menos frequente do que $H$. parviflora, habitando áreas de vegetação menos densa. No Brasil, está distribuída na região Norte no Estado do Pará, no Nordeste do Estado da Bahia, no Centro-Oeste no Distrito Federal, no Sudeste nos Estados de Minas Gerais, Rio de Janeiro e São Paulo e no Sul nos Estados do Paraná, Rio Grande do Sul e Santa Catarina (Barros et al. 2015).
Material examinado: BRASIL. SÃo PAUlo: Campos do Jordão, 17-II-2013, G.F. Gonçalves 16 (MACK); idem, 17-II-2013, G.F. Gonçalves 17 (MACK); idem, 21-III-2013, G.F. Gonçalves 34 (MACK).

Material adicional examinado: BRASIL. Distrito Federal: Brasília, 16-I-1995, B.M.T. Walter \& N.R. Oliveira 2333 (SP); Golás: Pirenópolis, 10-I-1981, N.L. Menezes s.n. (SP195329); Minas Gerais: Grão Mogol, 22-V-1982, N. Hensold et al. 3467 (SP); Jaboticatubas, 6-II-1972, M. Sazima 13395 (UEC); idem, 22-XIII-1972, A.B. Joly \& J. Semir 3197 (UEC); Mato Grosso: Poconé, 2-II-1993, A.L. Pedro et al. 2874 (UEC); idem, 21-II-1992, A.L. Prado 2499 (UEC); idem, 22-II-1994, A.L. Prado 2499 (UEC); ParanÁ: Guaratuba, 20-X-1976, G. Hastchbach 39141 (UEC); Morretes, 20-X-1928, F.C. Hoehne s.n. (SP23103); Paranaguá, 30-IX-1950, G. Hatschbach 10609 (SP); Ponta Grossa, 20-II-1948, G. Tessman s.n. (SP 69695); Rio de Janeiro: Itatiaia, 26-II-1921, P.C. Porto 993 (SP); Rio Grande do Sul: Bom Jesus, II-1930, $J$. Dutra 1083 (SP); idem, II-1928, J. Dutra 1071 (SP); Porto Alegre, 5-XII- 1932, C. Orth \& J Dutra s.n. (SP50512); Rio Grande, 29-XI-1978, J.L. Weachter 1046 (SP); São PaUlo: Campinas, 15-IX-2000, E.R. Pansarin 714 (UEC); idem, 25-IX-1981, A.O.S. Vieira et al. 13026 (UEC); Campos do Jordão, 13-I-2013, T.E. Barreto (SPSF); idem, 2-I-1995, J.E. Leite 3818 (SP); Iguape, XII-1921, A.C. Brade 8137 (SP); Piracicaba, 1-X-1984, E.L.M. Catharino 208 (SP).

Hadrolaelia mantiqueirae (Fowlie) Chiron \& V.P. Castro, Richardiana 2(1): 21. 2002.

Figura $1 \mathrm{~g}$

Epífita, simpodial, raízes fasciculadas, filiformes; cauloma intumescido em pseudobulbo, oval, 0,5-2,5 × 0,3-0,7 cm, 1-foliado no ápice, envolto por bainhas adpressas, imbricadas, escariosas. Folhas lanceoladas, coriáceo-carnosas, 1,2-3,5 × 0,5-1,5 cm, ápice acuminado, base séssil. Inflorescência uniflora, glabra. Flores vermelhas a vermelho-alaranjadas; sépala dorsal oblonga, 1,5-2 × 0,5-0,7 cm, ápice arredondado, base séssil; sépalas laterais oblongas, 1,5-2,1 × 0,5-1 cm, ápice arredondado a acuminado, base séssil; pétalas obovadas, 1,7-2,5 × 1-2 cm, ápice arredondado, base atenuada; labelo trilobado, 1,3-1,7 × ca. $1,6 \mathrm{~cm}$, lobos laterais trapeziformes, lobo central linear, ápice acuminado; ginostêmio cilíndrico, 0,3-0,5 cm compr.; polínias não vistas; ovário + pedicelo $2-3 \mathrm{~cm}$ compr.

Espécie epífita, encontrada sobre árvores isoladas no campo e na borda da mata. São bastante 
características da espécie, as flores vermelhas a vermelho-alaranjadas, vistosas, grandes em relação ao tamanho da planta. É endêmica do Brasil, ocorrendo na região Sudeste nos Estados de Minas Gerais, Rio de Janeiro e São Paulo e no Sul, nos Estados do Paraná, Rio Grande do Sul e Santa Catarina (Barros et al. 2015).

Material examinado: BRASIL. São PaUlo: Campos do Jordão, 16-II-2013, G.F. Gonçalves 10 (MACK); idem, 26-IX-2013, G.F. Gonçalves 40 (MACK).

Material adicional examinado: BRASIL. SANTA Catarina: Bom Jardim da Serra, 8-XII-1995, E.L. Borba et al. 161 (UEC); SÃo Paulo: Campos do Jordão, 29-IX-1984, L.A. Souza et al 16529 (UEC); idem, 20-IX-1991, S. Buzato \& M. Sazima 26860 (UEC); idem, 29-IX-1976, P.H. Davis et al. 2983 (UEC); São Bento do Sapucaí, 18-VIII-1994, J.Y. Tamashiro et al. 570 (UEC).

Octomeria gracilis Lodd. ex Lindl., Edwards's Bot.

Reg. 24 (misc.): 36.1838.

Figura $1 \mathrm{~h}$

Epífita, simpodial, raízes fasciculadas, filiformes; rizoma inconspícuo; cauloma não intumescido em pseudobulbo, 3-12,5 cm compr., envolto por bainhas simples, escariosas. Folhas lineares, carnosas, tríquetras, falcadas, 3-15,5 cm compr., ápice agudo, base séssil. Inflorescência em fascículo, apical, glabra. Flores amarelas, muitas vezes sucessivas; sépala dorsal lanceolada, 0,5-0,8 × 0,2-0,4 cm, ápice acuminado, base séssil; sépalas laterais lanceoladas, 0,5-0,8 $\times 0,2-0,4 \mathrm{~cm}$, ápice acuminado, base séssil; pétalas lanceoladas, $0,4-0,7 \times 0,2-0,3 \mathrm{~cm}$, ápice acuminado, base séssil; labelo trilobado, auriculado, $0,3-0,5 \times 0,2-0,3 \mathrm{~cm}$; ginostêmio cilíndrico, ca. $0,2 \mathrm{~cm}$ compr.; ovário articulado com o pedicelo, ovário + pedicelo ca. $4 \mathrm{~cm}$ compr. polínias não vistas.

Espécie epífita, com ocorrência limitada a uma região em que houve uma modificação da fisionomia de uma área de aproximadamente 10 a 15 metros por meio de intervenção humana, pela construção de uma bica que produz níveis diferenciados de umidade para a área, além da plantação de espécies exóticas de Pinus que favorecem a retenção da umidade e geram um sombreamento não usual para um campo de altitude. É endêmica do Brasil, estando presente na região Sudeste, nos Estados do Espírito Santo, Minas Gerais, Rio de Janeiro e São Paulo e no Sul, nos Estados Paraná, Rio Grande do Sul e Santa Catarina (Barros et al. 2015).
Material examinado: BRASIL. São PAULO: São Paulo, Campos do Jordão, 16-II-2013, G.F. Gonçalves 3 (MACK).

Material adicional examinado: BRASIL. PARANÁ: Paranaguá, 28-XIII- 1987, W.S. Souza \& R.M. Britez 1032 (SP); SÃo PaUlo: Campos do Jordão, 15-XII-1992, S. Xavier \& E. Caetano 332 (SPSF); Cananéia, 8-IX-1994, P.H. Miyagi et al. 184 (SP); idem, 28-IX-2005, R.P. Romanini et al. 229 (SP); Iguape, 25-VI-1992, D.F. Pereira et al 185 (SP); idem, 17-V-90, E.L.M. Catharino et al. 1390 (SP); São Miguel Arcanjo, 21-IX-1992, M Sugiyama \& M Kirizawa 996 (SPSF); idem, 31-XIII-2011, P.R.L. Moraes et al. 3276 (UEC); São Paulo, 15-IX-2008, A.P.P. Barbero 61 (SP); idem, 18-IX-1928, F.C. Hoehne \& M. Kuhlmann s.n. (SP23866); idem, 8-V-1924, A. Gehrt 9718 (SP); idem, 6-X-1936, F.C. Hoehne \& A. Gehrt s.n. (SP36500); idem, 20-IX-1920, F.C. Hoehne s.n. (SP4442).

Pelexia laminata Schltr., Anexos Mem. Inst. Butantan, Secc. Bot. 1(4): 22, t. 3. 1922.

Figura 1i

Terrícola, simpodial; raízes intumescidas, pilosas, cilíndricas a fusiformes; caule $16-40 \mathrm{~cm}$ compr. Folhas lanceoladas a estreitamente elípticas, verticiladas, membranáceas, 4-35 × 2,3-2,5 cm. Inflorescência em racemo, apical, pilosa, 4,5-9 $\mathrm{cm}$ compr. Flores brancas com listras verdes; sépala dorsal elíptico-lanceolada, pilosa na face abaxial, 1,5-2 ×0,6-0,8 cm, ápice caudado, base séssil; sépalas laterais lanceoladas, pilosas na face abaxial, falcadas, 1,7-2,3 × 0,5-0,6 cm, ápice acuminado a arredondado, base atenuada; pétalas espatuladas, assimétricas, 1,3-1,7 ×0,3-0,5 cm, ápice arredondado, base atenuada; labelo trilobado, lobos laterais com margens aderidas ao ginostêmio, lobo central depresso-obovado, 1,4-2,5 × 0,7-1,2 cm, dotado de carenas sub-triangulares, base formando mento globoso sob o ovário; ginostêmio cilíndrico, 0,6-0,7 cm compr.; rostelo linear 0,3-0,4 cm compr.; antera adnada ao ginostêmio; polínias 2, farinosas, claviformes, com viscídio; ovário + pedicelo 1,5-1,6 cm compr.

Essa espécie distingue-se das demais por sua inflorescência densamente pilosa, com flores brancas com listras verdes, possuindo um mento globoso sob o ovário. É endêmica do Brasil ocorrendo na região Norte, no Estado do Pará, no Centro-Oeste no Distrito Federal e no Estado de Goiás, no Sudeste nos Estados de Minas Gerais e São Paulo e no Sul, Estado do Paraná (Barros et al. 2015). 
Material examinado: BRASIL. SÃo PAULO: Campos do Jordão, 17-II-2013, G.F. Gonçalves 4 (MACK); idem, 17-II-2013, G.F. Gonçalves 19 (MACK); idem, 17-II-2013, G.F. Gonçalves 20 (MACK); idem, 21-III-2013, G.F. Gonçalves 33 (MACK).

Material adicional examinado: BRASIL. São PAULO: Franco da Rocha, 14-II-2002, J.B. Baitello 1106 (SPSF); idem, 17-III-2003, J.B. Baitello \& F.S. Peres 1476 (SPFS); Santo André, 15-III-1925, A. Gehrt s.n. (SP129052).

Prescottia stachyodes (Sw.) Lindl., Edward's Bot. Reg. 22: sub t. 1915 (“t. 1916”). 1836.

Figura $1 \mathrm{j}, 2 \mathrm{c}$

Terrícola, simpodial; raízes intumescidas, cilíndricas, pilosas; cauloma não intumescido em pseudobulbo; caule inconspícuo. Folhas pecioladas, elípticas a largo-elípticas; pecíolo 4-26 cm de compr., lâmina 7-30 × 4-12,5 cm, margem lisa ou denteada, ápice acuminado, base atenuada. Inflorescência em espiga, lateral, pedúnculo $43-80 \mathrm{~cm}$ compr., raque 12,5-35 cm compr., brácteas florais par descentes, ca. $7 \times 1 \mathrm{~cm}$. Flores verdes; sépala dorsal lanceolada, 0,3-0,4 × 0,1-0,2 cm, ápice acuminado, base séssil; sépalas laterais lanceoladas, ca. $0,5 \times 0,2 \mathrm{~cm}$, ápice acuminado, base séssil; pétalas lineares, 0,3-0,4 $\times$ ca. $0,1 \mathrm{~cm}$, ápice acuminado, base séssil; labelo cuculado, envolvendo o ginostêmio, ca. $0,5 \times 0,4 \mathrm{~cm}$, ápice acuminado, base atenuada; ginostêmio ca. $0,2 \mathrm{~cm}$ compr.; polínias 2, farinosas, claviformes, ovário intumescido, ca. 0,6 cm compr.

Espécie encontrada apenas na serapilheira próxima ao tronco de uma árvore, na borda do campo. Tem como principais características: folhas pecioladas, inflorescências eretas com flores abundantes, sésseis, esverdeadas e com o labelo cuculado. Possui ampla distribuição estando presente na região Norte nos Estados do Amazonas e Pará, no Nordeste nos Estados de Alagoas, Bahia, Ceará, Paraíba e Pernambuco, no Centro-Oeste no Distrito Federal e Estado de Goiás, no Sudeste nos Estados do Espírito Santo, Minas Gerais, Rio de Janeiro e São Paulo e na região Sul nos Estados do Paraná, Rio Grande do Sul e Santa Catarina (Barros et al. 2015).

Material examinado: BRASIL. SÃo PAULO: Campos do Jordão, 15-II-2014, G.F. Gonçalves 47 (MACK); BRASIL. São Paulo: Botucatu, 30-06-2014, G.M. Marcusso 343 (SPSF).

Material adicional examinado: BRASIL. Minas GeraIs: Camanducaia, 18-XII-2002, L.D. Meireles et al. 1083 (UEC); Carrancas, 22-VI-1998, R.B. Singer
98/48 (UEC); idem, 20-V-1997, R.B. Singer 97/50 (UEC); Descoberto, 30-IX-2000, F.R.G. Salimena s.n. (SP348415); Serra da Água Limpa, 2-I-1921, F.C. Hoehne s.n. (SP4870); ParanÁ: Morretes, 18-V-1982, G. Hatschbach 44941 (SP); Paranaguá, 4-V-1986, S.M. Silva 25016(UEC); idem, 21-IV-1999, C. Kozera \& V.A.O. Dittrich 1047 (UEC); SANTA Catarina: Brusque, 2-X-1949, P.R. Reitz 3027 (SP); SÃo Paulo: Amparo, 26-VIII-1943, M. Kuhlmann 1050 (SP); Campinas, 5-VII-1997, R.B. Singer 97/60 (UEC); Campos do Jordão, VI-1945, J.E. Leite 3493 (SP); idem, 28-III-1994, I. Cordeiro et al. 1293 (SP); idem, 22-VIII-1938, G. Hashimoto s.n. (SP40474); Cananéia, 30-VI-2002, T.B. Brier \& R.B. Singer 303 (UEC); Cunha, 15-VIII-1999, R.B. Singer 99/08 (UEC); Embu-Guaçu, 1-XI-1996, A. Rapini et al 233 (SP); Igaratá, 12-XIII-1951, M. Kuhlmann 2742 (SP); Itatiba, 7-VIII-1998, R.B. Singer 98/152 (UEC); Jundiaí, 3-X-2004, E.R. Pansarin 1161 (UEC); idem, 10-IX-1997, E.R. Pansarin 97/69 (UEC); Pirajussara, 3-XI-1930, A. Gehrt s.n. (SP26678); idem, 23-X-1923, F.C. Hoehne s.n. (SP29237); São Lourenço da Serra, 26-IV-2011, J.A. Lombardi et al. 8526 (UEC); São Paulo, 19-IX-1980, S.L. Jung 328 (SP); idem, 12-III-1980, M. Kirizawa 544 (SP); idem, 29-VI-1938, O. Handro s.n. (SP48277); idem, 30-X-1926, M. Kuhlmann s.n. (SP29235); idem, 12-VII-1943, A. Gehrt s.n. (SP5712).

Sacoila lanceolata (Aubl.) Garay, Bot. Mus. Leafl. 28 (4): 352.1982.

Figura $1 \mathrm{k}$

Terrícola, simpodial; raízes intumescidas, pilosas, cilíndricas a fusiformes; caule $14-73,5 \mathrm{~cm}$ compr. Folhas basais, rosuladas, linear-lanceoladas, membranáceas, muitas vezes ausentes na antese, 2,5-22 × 0,7-3,5 cm, ápice acuminado, base séssil. Inflorescência em racemo, apical, ereta, pilosa, 4-16,5 cm compr. Flores inteiramente avermelhadas a rosadas; sépala dorsal lanceolada, pilosa na face abaxial, 1,5-2,2 × 0,5-0,6 cm, ápice agudo, base séssil; sépalas laterais lanceoladas, pilosas na face abaxial, 1,6-2,5 × 0,3-0,5 cm, ápice agudo, base séssil; pétalas lanceoladas, assimétricas, 1,5-2,2 × 0,3-0,5 cm, ápice acuminado, base atenuada; labelo rômbico, 1,4-2,5 × 0,5-0,7 cm, ápice acuminado, base séssil, densamente pilosa, margens aderentes ao ginostêmio; ginostêmio cilíndrico, ca. $0,2 \mathrm{~cm}$ compr.; rostelo proeminente, aciculado, ca. 0,4 cm compr.; antera opercular, adnada ao ginostêmio; polínias 2, farinosas, claviformes, com viscídio; ovário fusiforme, ovário + pedicelo ca. $1 \times 0,4 \mathrm{~cm}$. 
É comum a espécie apresentar-se áfila durante a antese, porém também foi observada a presença de folhas durante a floração de alguns indivíduos. A inflorescência é caracteristicamente pilosa, e as flores vistosas, de tom avermelhado. Possui ampla distribuição geográfica ocorrendo nas Américas. No Brasil, ocorre no Norte nos Estados do Amazonas, Amapá e Pará, no Nordeste, nos Estados de Alagoas, Bahia, Maranhão, Paraíba, Pernambuco e Sergipe, no Centro-Oeste, no Distrito Federal e Estados de Goiás e Mato Grosso, no Sudeste, nos Estados do Espírito Santo, Minas Gerais, Rio de Janeiro e São Paulo e no Sul, nos Estados do Paraná, Rio Grande do Sul e Santa Catarina (Barros et al. 2015).

Material examinado: BRASIL. São PAUlo: Campos do Jordão, 25-IX-2013, G.F. Gonçalves 36 (MACK).

Material adicional examinado: BRASIL. BAHIA: Água Preta, 4-VIII-1936, J. Robanuts 5056 (SP); Distrito FEDERAL: Samambaia, 30-VIII-1995, J.M.R. Rezende 80 (SP); Espírito SANTO: Linhares, 13-VII-2005, R.B. Singer \& S. Koehler s.n. (UEC027127); Collatina, 1-III-1939, M.B. Foster s.n. (SP41445); Minas Gerais: Belo Horizonte, 4-IX-1945, L.O. Williams \& V. Assis 7459 (SP); idem, 5-IX-1933, M. Barreto 4876 (SP); Caldas, s.d., I. Regnell 422 (SP); Carrancas, 19-IX-1998, A.O. Simões \& R.B. Singer 271 (UEC); Diamantina, 10-II-1992, F.A. Vitta \& R. Belinello 588 (UEC); Extrema, 24-X-2009, G.H. Shimizu 222 (UEC); Jaboticatubas, 3-IX-1972, M. Sazima 13410 (UEC); Lavras, 4-IX-1987, D.A. Carvalho et al. s.n. (SP218983); idem, s.d., E.P. Heringer 771 (SP); Monte Belo, 7-IX-1981, M.C. Weyla 195 (SP); Ouro Preto, 30-III-1902, R.A. Guimarães s.n. (SPSF3830); Passa-quatro, 28-VIII-2013, L.N. Gonçalves et al. 108 (SPSF); Poços de Caldas, 92-X-1980, F.R. Martins et al. 224 (UEC); PARANÁ: Apucarana, 1-X-1999, D.A. Estevan et al. 119 (SP). Guaratuba, 2-X-1929, F.C. Hoehne s.n. (SP24521); Tamarana, 17-IX-1998, L.C.B. Azevedo et al. s.n. (SP409314); União de Vitória, 12X-1965, H.D. Bicalho 75 (SP); idem, 5-XI-1964, H.D. Bicalho s.n. (SP221782); Piauí: Caracol, 14-X-1999, A.P. Franco et al. s.n. (SP37529); Rio de JANEIRO: Petrópolis, IX-1929, C. Spannagel 27 (SP); Rio GrandE Do Sul: Lavras do Sul, 21-IX-1998, J.R. Stehmann et al. 2051 (UEC); Nova Friburgo, 20-IX-1999, R.B. Singer 94/16 (UEC); SANTA CATARINA: Bom Jardim da Serra, 19-IX-1998, E.L. Borba et al. 162 (UEC); São Joaquim, 20-XII-1963, J. Mattos 11318 (SP); Urubici, 6-XII-1995, E.L. Borba et al. 163 (UEC); SÃo PAULO: Botucatu, 19-IX-1972, A. Amaral Jr 1077 (SP); Campinas, 12-IX-1978, W. Marcondes-Ferreira 8449
(UEC); Campos do Jordão, 10-XI-1994, S. Buzato \& S. Vogel 32531 (UEC); idem, 9-X-1992, S. Buzato \& R.B. Singer 28011 (UEC); Congonhas, 29-IX-1936, $M$. Barreto 5181 (SP); Corumbataí, 20-VIII-1995, M.A. Assis et al. 565 (UEC); Paranapanema, 26-IX-2007, C.R. Lima et al. 78 (SPSF); São Paulo, 30-IX-1906, A. Usteri s.n. (SP29087).

Skeptrostachys balanophorostachya (Rchb.f. \& Warm.) Garay, Bot. Mus. Leafl. 30: 359. 1982 [1980].

Figura 11,2 d

Terrícola, simpodial; cauloma não intumescido em pseudobulbo; caule 20-43 cm compr. Folhas basais, rosuladas, sésseis, estreitamente-elípticas a lanceoladas, membranáceas, 7-18,5 × 1,3-3 cm, ápice acuminado, base atenuada. Inflorescência em espiga, apical, ereta, pilosa, 5,5-22 $\mathrm{cm}$ compr., brácteas 2-2,5 cm compr. Segmentos florais brancos na face adaxial e castanho-claros na face abaxial; sépala dorsal lanceolada, 0,9-1,3 × 0,3-0,5 cm, ápice agudo, base séssil; sépalas laterais lanceoladas, $1-1,4 \times 0,3-0,5 \mathrm{~cm}$, ápice acuminado, base séssil; pétalas lanceoladas, 0,9-1,2 × 0,3-0,5 cm, ápice acuminado, base séssil; labelo trilobado, auriculado, 0,8-1,2 $\times 0,3-0,7 \mathrm{~cm}$, ápice arredondado, base atenuada, margens aderentes ao ginostêmio; ginostêmio cilíndrico, ca. $0,3 \mathrm{~cm}$ compr., rostelo aciculado, ca. $1 \mathrm{~cm}$ compr.; polínias 2, farinosas, com viscídio; ovário ca. $0,7 \mathrm{~cm}$ compr.

Tem como características importantes sua inflorescência pilosa, em espiga, vistosa, com muitas flores pequenas e de cor branca com brácteas longas. Tem ocorrência para a região Centro-Oeste no Estado do Mato Grosso, no Sudeste nos Estados de Minas Gerais, Rio de Janeiro e São Paulo, e no Sul nos Estados do Paraná, Rio Grande do Sul e Santa Catarina (Barros et al. 2015).

Material examinado: BRASIL. São PAULo: Campos do Jordão, 17-II-2013, G.F. Gonçalves 21 (MACK); idem, 17-II-2013, G.F. Gonçalves 23 (MACK).

Material adicional examinado: BRASIL. São PAULO: Botucatu, 8-IV-1996, L.R.H. Bicudo et al. 924 (SP); Campos do Jordão, 30-II-1940, G. Hashimoto s.n. (SP42852); idem, III-1946, J.B. Leite 4067 (SP); São Bernardo, 5-II-1934, F.C. Hoehne s.n. (SP31741); São José dos Campos, 27-VII- 1962, I. Mimura 435 (SP); São Paulo, 22-II-1923, A. Gehrt s.n. (SP8387); idem, 1-V-1943, O. Handro s.n. (SP48304); idem, 17-III-1930, A. Gehrt s.n. (SP25247); idem, 8-V-1924, A. Gehrt s.n. (SP9708); idem, 18-VI-1934, H. Zellibor 11 (SP). 
Outros trabalhos realizados em campos de altitude, em regiões diferentes, mostraram resultados próximos, quanto ao número de espécies de Orchidaceae encontradas na área estudada. Caiafa \& Silva (2005), estudando um campo de altitude no Parque Estadual da Serra do Brigadeiro, encontraram oito gêneros e 13 espécies; já Mocochinski \& Sheer (2008), trabalhando com campos de altitude da Serra do Mar Paranaense, encontraram 10 gêneros e 12 espécies. Barbarena (2010) também obteve resultados próximos aos aqui apresentados para os campos de altitude do Parque Nacional do Itatiaia, com seis gêneros e 17 espécies. Já Rezende et al. (2013), estudando a flora vascular da Serra da Pedra Branca (MG), encontraram 16 gêneros e 29 espécies, mas nesse caso deve-se ressaltar que $70 \%$ da área de estudo era composta por campos de altitude, além de ser uma área relativamente maior, o que pode justificar a maior diversidade de espécies com relação às outras regiões. Apesar disso, é importante ressaltar algumas dificuldades e problemas ambientais da região de Campos do Jordão, que podem ter interferido na representatividade original de espécies, como, por exemplo, a presença de espécies exóticas e o avanço das áreas urbanas.

Quanto aos fatores limitantes durante o período de coletas, pode-se citar o tamanho e distância entre os quatro fragmentos, o que muitas vezes impossibilitava a visita aos quatro fragmentos numa mesma expedição. Outros fatores que foram observados em alguns dos fragmentos e que representam uma ameaça à conservação e à diversidade desse tipo de vegetação foram: a ocorrência de espécies exóticas invasoras, como, por exemplo, Pinus spp., que, em alguns casos, chegou a formar pequenos bosques dentro do campo, substituindo parte da vegetação original; existência de exemplares de Pinus spp. propositalmente plantadas em um dos campos para fins puramente ornamentais, próximo a uma fonte de água corrente que corta uma das trilhas; e a presença de animais domesticados como cães e cavalos passeando nas trilhas.

A abertura e uso de trilhas para fins turísticos e de recreação também são fatores antrópicos muito prejudiciais a esse tipo de vegetação, já que também foi observada a presença de profissionais contratados para aparar parte da vegetação nas proximidades de algumas das trilhas mais visitadas. Outra questão que causou preocupação durante o estudo foi o avanço das áreas urbanas que ameaça a integridade dessas áreas já naturalmente pouco valorizadas, como pôde ser observado em um dos fragmentos que se encontrava muito próximo a um condomínio residencial, e no qual, em todas as expedições realizadas, foi constatada a presença de lixo descartado de forma indevida e a presença de um cano de eliminação de esgoto escoando para dentro do campo. Houve também um incêndio nesse mesmo fragmento que consumiu grande parte da vegetação ao longo de uma grande parcela da área.

A região de Campos do Jordão é uma área reconhecidamente rica em espécies vegetais nativas e, especialmente quanto a Orchidaceae, pelo grande número de coletas já registradas para o munícipio. Entretanto, essa riqueza se encontra muito ameaçada devido à ação humana na região que possui um grande apelo turístico e influência da estética europeia, e consequentemente sua vegetação natural acaba sendo muitas vezes negligenciada, com a introdução de espécies exóticas ornamentais e até mesmo pela degradação de áreas de proteção ambiental pela falta de conscientização e educação ambiental por parte da população. Por conseguinte, mais estudos deveriam ser realizados na região, principalmente em áreas de campos de altitude, que são áreas tão ricas, singulares e pouco estudadas e que vem sofrendo grande pressão antrópica que ameaça sua preservação e não só na área estudada, mas também em muitas outras regiões aonde há ocorrência desse tipo de vegetação como relataram Mochochinski \& Scheer (2008).

\section{Agradecimentos}

Agradeço ao Dr. Adriano Monteiro de Castro, pela colaboração na elaboração deste artigo e todo o suporte oferecido. Ao Instituto Presbiteriano Mackenzie, por me permitir o acesso à área de estudo e disponibilizar recursos para a conclusão do trabalho. Ao $\mathrm{CNPq}$, pela bolsa de Iniciação Científica ao primeiro Autor, dentro do programa PIBIC e bolsa de Produtividade em Pesquisa ao segundo Autor.

\section{Literatura citada}

Arzolla, F.A.R.D.P., Paula, G.C.R., Chautems, A.P. \& Shepherd, G.J. 2007. O primeiro registro de Sinningia grantifolia Chautems (Gerneriaceae) no estado de São Paulo. Biota Neotrópica 7: 374-377.

Atwood,J.T. 1986. The size of the Orchidaceae and the systematic distribution of epiphytic orchids. Selbyana 9: 171-186.

Barberena, F.F.V.A. 2010. Orchidaceae no Parque Nacional do Itatiaia, Sudeste do Brasil: listagem e estudos taxonômicos na subtribo Laeliinae. Dissertação de Mestrado, Instituto de Pesquisas Jardim Botânico do Rio de Janeiro, Rio de Janeiro.

Barros, F., Vinhos, F., Rodrigues, V.T., Barberena, F.F.V.A., Fraga, C.N., Pessoa, E.M. \& Forster, W. 2015. Orchidaceae. In: R.C. Forzza et al. (coords.). Lista de Espécies da Flora do Brasil. Jardim Botânico do Rio de Janeiro, Rio de Janeiro. Disponível em http:// floradobrasil.jbrj.gov.br/jabot/floradobrasil/FB179. (acesso em 10-VIII-2015). 
Benites, V.M., Caiafa, A.N., Mendonça, E.S., Schaefer, C.E. \& Ker, J.C. 2003. Solos e vegetação nos complexos rupestres de altitude da Mantiqueira e do Espinhaço. Floresta e Ambiente 10: 76-85.

Caiafa, A.N. \& Silva, A.F. 2005. Composição florística e espectro biológico de um campo de altitude no Parque Estadual da Serra do Brigadeiro. Minas Gerais - Brasil. Rodriguésia 56: 163-173.

Chase, M.W., Cameron, K.M., Barrett, R.L. \& Freudenstein, J.V., Pridgeon, A.M., Salazar, G., Van den Berg, C. \& Schuiteman, A. 2015. An updated classification of Orchidaceae. Botanical Journal of the Linnean Society 177: 151-174.

Cogniaux, A. 1893-1896. Orchidaceae. In: C.F.P. Martius, A.W. Eichler \& I. Urban (eds.). Flora brasiliensis. Frid. Fleischer, Lipsiae, v. 4, pars 4, pp. 1-672.

Cogniaux, A. 1898-1902. Orchidaceae. In: C.F.P. Martius, A.W. Eichler \& I. Urban (eds.). Flora brasiliensis. Frid. Fleischer, Lipsiae, v. 4, pars 5, pp. 1-663.

Cogniaux, A. 1904-1906. Orchidaceae. In: C.F.P. Martius, A.W. Eichler \& I. Urban (eds.). Flora brasiliensis. Frid. Fleischer, Lipsiae, v. 4, pars 6, pp. 1-604.

Dressler, R. L. 1981. The Orchids, natural history and classification. Harvard University Press, Cambridge.

Dressler, R.L. 1993. Phylogeny and classification of the orchid family. Cambridge University Press, Cambridge.

Dressler, R.L. 2005. How many orchids species? Selbyana 26: $155-158$.

Guimarães, L.R.S. 2010. Flora da Serra do Cipó (Minas Gerais, Brasil): Orchidaceae - subfamilia Vanilloideae e subtribos Dendrobiinae, Oncidiinae, Maxilariinae (subfamilia Epidendroideae), Goodyerinae, Spiranthinae e Cranichidinae (subfamilia Orchidoideae). SP, Brasil. Dissertação de Mestrado, Instituto de Botânica, São Paulo.

Hoehne, F.C. 1949. Iconografia das Orchidaceas do Brasil. Secretaria da Agricultura, São Paulo.

Instituto Brasileiro de Geografia e Estatística. 1992. Manual técnico da vegetação brasileira, Instituto Brasileiro de Geografia e Estatística, Rio de Janeiro.

Lindley, J. 1830-1840. Genera and Species of Orchidaceous Plants. Ridways, London.

Martinelli, G. 2007. Mountain biodiversity in Brazil. Revista Brasileira de Botânica 30: 587-597.

Mocochinski, A.Y. \& Scheer, M.B. 2008. Campos de altitude na Serra do Mar paranaense: Aspectos florísticos. Revista Floresta 38: 625-640.

Pereira-Silva, E.F.L., Hardt, E. \& Francisco, C.E.S. 2007. Caracterização florística da vegetação lenhosa de um fragmento urbano de floresta ombrófila mista alto montana, Campos do Jordão, SP. HOLOS Environment 7: 154-170.

Pridgeon, A.M., Cribb, P.J., Chase, M.W. \& Rasmussen, F.N. 2001. Genera Orchidacearum v. 2: Orchidoideae (part 1). Oxford University Press, New York.

Pridgeon, A.M., Cribb, P.J., Chase, M.W. \& Rasmussen, F.N. 2003. Genera Orchidacearum. v. 3, Orchidoideae (part 2), Vanilloideae. Oxford University Press, New York.
Pridgeon, A.M., Cribb, P.J., Chase, M.W. \& Rasmussen, F.N. 2005. Genera Orchidacearum. v. 4, Epidendroideae (part one). Oxford University Press, New York.

Pridgeon, A.M., Cribb, P.J., Chase, M.W \& Rasmussen, F.N. 2009. Genera Orchidacearum v. 5, Epidendroideae (part two). Oxford University Press, New York.

Pabst, G.F.J, \& Dungs F. 1975. Orchidaceae Brasilienses I. Kurt Schmersow, Hildesheim.

Pabst, G.F.J, \& Dungs F. 1977. Orchidaceae Brasilienses II.: Kurt Schmersow Hildesheim.

Pinheiro, F., Barros, F. \& Lourenço, R. 2004. A. O que é uma orquídea? In: F. Barros \& G.B. Kerbauy (orgs.). Orquidologia sul-americana: uma compilação científica. Secretaria do Meio Ambiente, São Paulo, pp. 11-33.

Radford, A.E., Dickson, W.C., Massey, J.R. \& Bell, C.R. 1974. Vascular plant systematics. Harper Collins, New York.

Rezende, M.G., Elias, R.C.L., Salimena, F.R.G. \& Neto, L.M. 2013. Flora vascular da Serra da Pedra Branca, Caldas, Minas Gerais e relações florísticas com áreas de altitude da região sudeste do Brasil. Biota Neotropica 13: 201-224.

Ribeiro, K.T., Medina, B.M.O. \& Scarano, F.R. 2007. Species composition and biogeographic relations of the rock outcrop flora on the high plateau of Itatiaia, SE-Brazil. Revista Brasileira de Botânica 30: 623-639.

Robim, M.J. \& Pfeifer, R.M. 1989. Correlações de características do meio biofísico do Parque Estadual de Campos do Jordão, SP. Acta Botanica Brasilica 2: $175-181$.

Rodrigues, J.B. 1877. Genera et Species Orchidearum Novarum vol. 1. Typographia Nacional, Rio de Janeiro.

Rodrigues, J.B. 1882. Genera et Species Orchidearum Novarum v. 2. Typographia Nacional, Rio de Janeiro.

Rosa, D.A. \& Affonso, P. 2009. Levantamento do gênero Oncidium Sw. sensu lato (Orchidaceae) no núcleo Curucutu, Parque Estadual da Serra do Mar, São Paulo. Revista do Instituto Florestal 21: 55-62.

Safford, H.D. 1999. Brazilian páramos I. An introduction to the physical environment and vegetation of the campos de altitude. Journal of Biogeography 26: 693-712.

Silva, I.V., Meira, R.M.S.A., Azevedo, A.A. \& Euclydes, R.M.A. 2006. Estratégias anatômicas foliares de treze espécies de Orchidaceae ocorrentes em um campo de altitude no Parque Estadual da Serra do Brigadeiro (PESB) - MG, Brasil. Acta Botanica Brasilica 20: 741-750.

Sprunger, S.1986. Orchids from Curtis's Botanical Magazine. Cambridge University Press, Cambridge.

Stehmann, J.R., Forzza, R.C., Salino, A., Sobral, M., Costa, D.P. \& Kamino, L.H.Y. 2009. Plantas da Floresta Atlântica. Jardim Botânico do Rio de Janeiro, Rio de Janeiro.

Vasconcellos, M.F.D. 2011. O que são campos rupestres e campos de altitude nos topos de montanha do Leste do Brasil? Revista Brasileira de Botânica 34: 241-246.

Veloso, H.P., Rangel Filho, A.L.R. \& Lima, J.C.A. 1991. Classificação da vegetação brasileira adaptada a um sistema universal. IBGE, Rio de Janeiro. 